\title{
Determinação da segurança biológica do xampu de cetoconazol: teste de irritação ocular e avaliação do potencial de citotoxicidade in vitro
}

\author{
Inara Staub ${ }^{1 *}$, Áurea Silveira $\mathrm{Cruz}^{2}$, Terezinha de Jesus Andreoli Pinto ${ }^{3}$, \\ Elfrides Eva Scherman Schapoval', Ana Maria Bergold'
}

1 Faculdade de Farmácia, Universidade Federal do Rio Grande do Sul, ${ }^{2}$ Seção de Culturas Celulares, Instituto Adolfo Lutz, ${ }^{3}$ Departamento de Farmácia, Faculdade de Ciências Farmacêuticas, Universidade de São Paulo

* Correspondência:

I. Staub

Faculdade de Farmácia

Universidade Federal do Rio Grande do Sul

Av. Ipiranga 2752, sala 703

90610-000 - Porto Alegre - RS, Brasil

E-mail: inarastaub@cav.udesc.br
Cetoconazol é um agente antifúngico, que pode ser incorporado em diferentes formas farmacêuticas, como, por exemplo, xampus e cremes. O objetivo do trabalho foi avaliar a segurança biológica in vivo (teste de irritação ocular) $e$ in vitro (teste de citotoxicidade) do xampu de cetoconazol degradado sob ação da luz. Para tanto, a formulação foi exposta à radiação $U V-C(254 \mathrm{~nm})$ e foram empregados dois métodos para a determinação quantitativa do cetoconazol: CLAE e ensaio microbiológico. Os resultados demonstraram alteração do cetoconazol em presença da luzpresença de picos secundários no cromatograma e diminuição da atividade antifúngica - entretanto, não demonstraram alteração na segurança biológica entre xampu de cetoconazol e xampu de cetoconazol contendo produtos de degradação.
Unitermos

- Cetoconazol

- Xampu

- Produtos de degradação

- Teste de irritação ocular

- Teste de citotoxicidade

\section{INTRODUÇÃO}

As infecções causadas por fungos estão entre as causas mais comuns de doenças cutâneas. Dentre elas, podemse citar as malassezioses, que são as formas clínicas da infecção causada pela levedura Malassezia: pitiríase (tinha) versicolor, foliculite por Malassezia e alguns autores correlacionam o fungo Malassezia furfur ao desenvolvimento da dermatite seborréica (Gupta, Madzia, Batra, 2004; Klenk, Martin, Hefferman, 2003). Atualmente, o xampu de cetoconazol é uma forma de tratamento eficaz e amplamente utilizada para combater estas infecções.

O cetoconazol (Figura 1), pertencente à classe dos imidazóis, possui ação sistêmica e tópica, podendo ser incorporado em diversas formas farmacêuticas. O principal efeito dos imidazóis sobre os fungos é a inibição da esterol
14- $\alpha$-desmetilase prejudicando a síntese do ergosterol na membrana, inibindo o crescimento dos fungos (Benett, 1996).

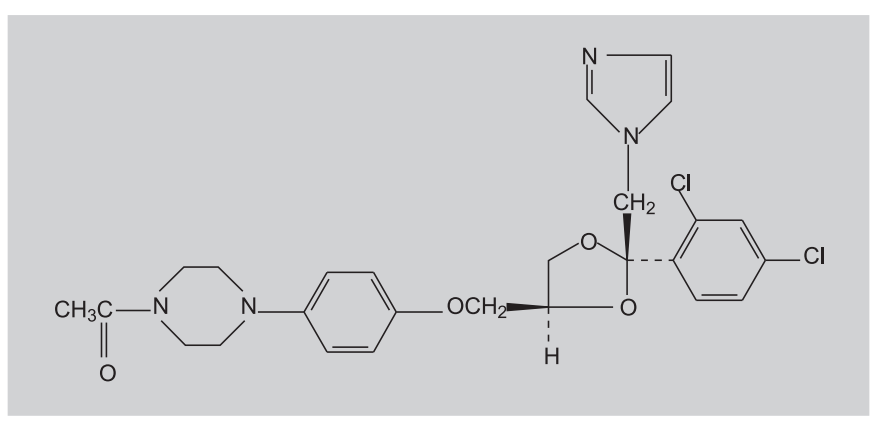

FIGURA 1 - Estrutura química do cetoconazol. 
Em geral, formulações de cetoconazol sofrem alteração muito rapidamente sugerindo a formação de produtos de degradação (Staub et al., 2002; Skiba et al., 2000; Allen, Erickson, 1996; Thoma, Kübler, 1996). Segundo Tonessen (2001), fármacos sensíveis à luz podem ser afetados pela luz solar (especialmente radiação ultravioleta) e por fonte de luz artificial (lâmpada fluorescente). A exposição inadequada à luz pode levar à fotodegradação da substância ativa, podendo formar um produto inativo, mas, também, pode alterar propriedades físico-químicas como alteração na coloração do produto. É conhecido que certos produtos de degradação apresentam maior toxicidade que a substância ativa que os originou (Nudelman, 1975). Por isso, é importante que durante os estudos de estabilidade de um produto seja avaliada a possível alteração na toxicidade do produto final.

Assim sendo, o objetivo do trabalho foi avaliar a segurança biológica da formulação de xampu de cetoconazol, após exposição do produto à luz e detecção de produtos de degradação, para verificar se os mesmos alteravam o grau de irritação do produto. Para tanto, foram empregados dois testes - teste de irritação ocular e avaliação do potencial de citotoxicidade in vitro - para posterior comparação dos resultados obtidos.

\section{MATERIAL E MÉTODOS}

\section{Xampu de cetoconazol}

Os excipientes empregados no preparo do xampu de cetoconazol $2 \%$ foram éter lauril sulfato de sódio, dietanolamida de ácido graxo de coco, metilparabeno, cloreto de sódio e água. Para solubilização do fármaco e ajuste do $\mathrm{pH}$ da formulação $(5,5)$ foram empregados $\mathrm{HCl}$ $M$ e $\mathrm{NaOH} M$, respectivamente.

\section{Avaliação da fotoestabilidade}

Amostras do xampu de cetoconazol foram acondicionadas em cubetas de plástico descartáveis Plastibrand ${ }^{\circledR}$, transparentes ao UV, e, em seguida, foram expostas à lâmpada UV-C (lâmpada Light express LE UV (254 nm), 30 W colocada em uma câmara, espelhada internamente, com 100 x 16 x $16 \mathrm{~cm}$. Juntamente com os testes de degradação do fármaco, avaliou-se a formulação do xampu base (contendo somente os excipientes) e amostras do xampu de cetoconazol revestidas com papel alumínio para proteção da luz.

As amostras expostas à luz UV-C foram avaliadas após 24 horas e quantificadas através de dois métodos desenvolvidos e validados: cromatografia líquida de alta efi- ciência (CLAE) (Staub, Bergold, 2004) e ensaio microbiológico (Staub, Schapoval, Bergold, 2005).

\section{Cromatografia líquida de alta eficiência}

As análises foram realizadas em cromatógrafo a líquido de alta eficiência SHIMADZU LC-10AD, detector de UV-Vis SPD-10AV, central de controle SCL-10A e desgaseificador DGU-14A. A fase móvel foi constituída de monoisopropilamina-metanol $(2: 500, \mathrm{v} / \mathrm{v}) /$ acetato de amônio-água $(1: 200, \mathrm{p} / \mathrm{v})(7: 3, \mathrm{v} / \mathrm{v})$ e pH final de 5,5 ajustado com ácido acético. As condições cromatográficas utilizadas foram fluxo de $1 \mathrm{~mL} / \mathrm{min}$, coluna LiChrospher ${ }^{\circledR}$ $100 \mathrm{RP}-8,5 \mu \mathrm{m}(150 \mathrm{~mm} \times 4,6 \mathrm{~mm})$, comprimento de onda de $225 \mathrm{~nm}$ e volume de injeção de $20,0 \mu \mathrm{L}$.

Para preparo da solução amostra foram pesados 0,4 g do xampu de cetoconazol e diluídos na fase móvel, sendo que a concentração de trabalho foi de $320 \mu \mathrm{g} / \mathrm{mL}$. Como referência foi preparada solução padrão contendo $300 \mu \mathrm{g} / \mathrm{mL}$ de cetoconazol substância química de referência. As amostras foram analisadas em triplicata e o desvio padrão relativo entre os teores obtidos foi calculado.

\section{Ensaio microbiológico}

O teor de cetoconazol presente no xampu foi determinado através do método de difusão em ágar - cilindros em placas, com delineamento $3 \times 3$. Os parâmetros empregados para a realização do ensaio foram os seguintes: Candida albicans ATCC 10231 como microrganismo teste, concentração do inóculo de $0,5 \%$, meio de cultura Ágar Sabouraud-dextrose $2 \%$, concentração das soluções de $20,0,100,0$ e $500,0 \mu \mathrm{g} / \mathrm{mL}$ e incubação das placas por 18 horas, $35 \pm 2{ }^{\circ} \mathrm{C}$. A determinação da potência do cetoconazol na amostra foi determinada pela equação de Hewitt (1977). O ensaio foi avaliado através de análise de variância (ANOVA), conforme preconizado pela F. Bras. IV (1988).

\section{AVALIAÇÃO DA SEGURANÇA BIOLÓGICA}

Foram avaliadas duas formulações de xampu de cetoconazol: amostra não degradada $(103,3 \%)$ e amostra degradada $(41,4 \%)$. Para a realização dos ensaios, as amostras não foram submetidas a tratamento prévio, como esterilização ou extração e foram aplicadas diretamente sem diluição.

\section{Teste de irritação ocular}

O procedimento, a seguir descrito, foi baseado no trabalho desenvolvido por Draize e colaboradores (1944). Os experimentos foram realizados em coelhos albinos, da raça Nova Zelândia com peso corpóreo de 2 a 2,5 kg. Uti- 
lizaram-se cinco coelhos para cada amostra. O trabalho foi aprovado pela Comissão de Ética em Experimentação Animal da FCF/USP (Protocolo CEEA n ${ }^{\circ}$ 94).

Com auxílio de uma seringa aplicou-se $0,1 \mathrm{~mL}$ do xampu no olho direito do coelho enquanto que o olho esquerdo serviu como controle. Em seguida as pálpebras foram mantidas unidas por 30 segundos, massageando-se o olho do animal para permitir o contato uniforme com o produto.

As avaliações das reações oculares foram baseadas na escala de Draize e colaboradores (1944). Analisaram-se os efeitos causados na região da córnea, como opacidade e área envolvida, na região da íris, como irite e região da conjuntiva, como hiperemia (superabundância de sangue), quemose (edema) e secreção. Essas reações foram observadas depois de decorridas $24,48,72$ horas e no final do sétimo dia após aplicação do produto. O valor final de cada animal foi obtido e a média dos cinco coelhos foi calculada, resultando no índice de irritação ocular.

\section{Avaliação do potencial de citotoxicidade in vitro}

Os ensaios foram realizados na Seção de Culturas Celulares do Instituto Adolfo Lutz (IAL). A linhagem celular empregada foi NCTC Clone 929, célula de tecido conjuntivo de camundongo (ATCC CCL-1). A linhagem foi cultivada em meio mínimo de Eagle, suplementado com 0,1 $\mathrm{mM}$ de aminoácidos não-essenciais, $1 \mathrm{mM}$ de piruvato de sódio e $10 \%$ de soro fetal bovino (MEM), sem antibiótico e incubadas a $36{ }^{\circ} \mathrm{C}$. A dispersão da monocamada celular foi efetuada utilizando uma associação de tripsina $0,2 \% \mathrm{e}$ versene $0,02 \%$.

O método utilizado foi difusão em ágar, segundo Farmacopéia Americana (USP 28, 2005). Para tanto, as células foram semeadas em volumes de $5 \mathrm{~mL}$ em placas de Petri $(60 \times 15 \mathrm{~mm})$, na concentração de $3 \times 10^{5}$ céls $/ \mathrm{mL}$. A incubação foi realizada por 48 horas a $37^{\circ} \mathrm{C} \mathrm{em}$ atmosfera úmida contendo $5 \%$ de $\mathrm{CO}_{2}$. Após este período, o meio de cultura foi desprezado e adicionado volume de $5 \mathrm{~mL}$ de overlay, em cada placa de Petri. Este meio é composto de partes iguais de MEM duas vezes concentrado e ágar (BBL-Becton Dickinson) a $1,8 \%$ contendo $0,01 \%$ de vermelho neutro (Merck), como corante vital. No momento do uso o ágar foi fundido e misturado com o MEM, ambos à temperatura de $44 \pm 1^{\circ} \mathrm{C}$.

As amostras de xampu foram colocadas em discos de papel de filtro atóxico que foram posicionados sobre a camada de ágar. As placas foram incubadas em estufa a $37^{\circ} \mathrm{C}$ com $5 \%$ de $\mathrm{CO}_{2}$ por 24 horas. Foram utilizados fragmentos de látex como controle positivo e discos de papel atóxico como controle negativo. Para a determinação de cada amostra utilizaram-se quatro placas. Após o período de incubação, as placas foram observadas macroscópica e microscopicamente e a citotoxicidade foi constatada pela presença de halo claro ao redor da amostra testada. Fez-se a determinação do tamanho do halo formado, com auxílio de paquímetro. A média das leituras das quatro placas foi calculada. A partir das medidas dos halos formados, os índices de zona (IZ) foram graduados segundo a Farmacopéia Americana (USP 28, 2005).

\section{RESULTADOS E DISCUSSÃO}

Recentemente, a decomposição de fármacos, como resultado da absorção da radiação luminosa, tem recebido maior atenção devido à estrutura química complexa de muitos compostos (Lachman, Lieberman, Kanig, 2001). A exposição à luz pode influenciar a estabilidade do produto levando a modificações físico-químicas, como coloração ou descoloração do produto; além disso, a exposição inapropriada à luz pode originar produtos tóxicos de fotodegradação.

Em trabalhos anteriores, foram desenvolvidos e validados dois métodos para doseamento do fármaco na forma farmacêutica xampu: CLAE e ensaio microbiológico. Atualmente, quase todos os ensaios de estabilidade de fármacos recorrem à CLAE como método de análise, pois esta consegue separar e quantificar a substância ativa juntamente com seus produtos de degradação (Watson, 2005). Além da CLAE, o ensaio microbiológico é muito útil, pois este esclarece dúvidas a respeito da possível perda de atividade da substância em análise (USP 28, 2005).

Com auxílio dos métodos desenvolvidos e validados foi possível avaliar a estabilidade do cetoconazol em xampu e verificar que o fármaco sofre degradação por ação da luz (Staub, 2005). Além da diminuição significativa nos teores das amostras e detecção de produtos de degradação nos cromatogramas (Figura 2), foi possível verificar intensa mudança de coloração da formulação. $\mathrm{O}$ xampu base exposto à luz UV-C e o xampu de cetoconazol revestido com papel alumínio não sofreram alterações, durante a exposição à luz. Através do ensaio microbiológico, verificou-se diminuição na atividade do cetoconazol em xampu, frente ao microrganismo teste (Candida albicans). A comparação entre as placas da amostra íntegra e degradada demonstrou que o produto diminui a atividade, pois os halos formados, após exposição do produto à luz, foram menores. Os resultados obtidos nesse estudo de estabilidade serão minuciosamente discutidos e publicados em um novo trabalho.

Após a constatação da diminuição da atividade do fármaco e detecção de produtos de degradação nos cromatogramas, procedeu-se à avaliação da segurança 


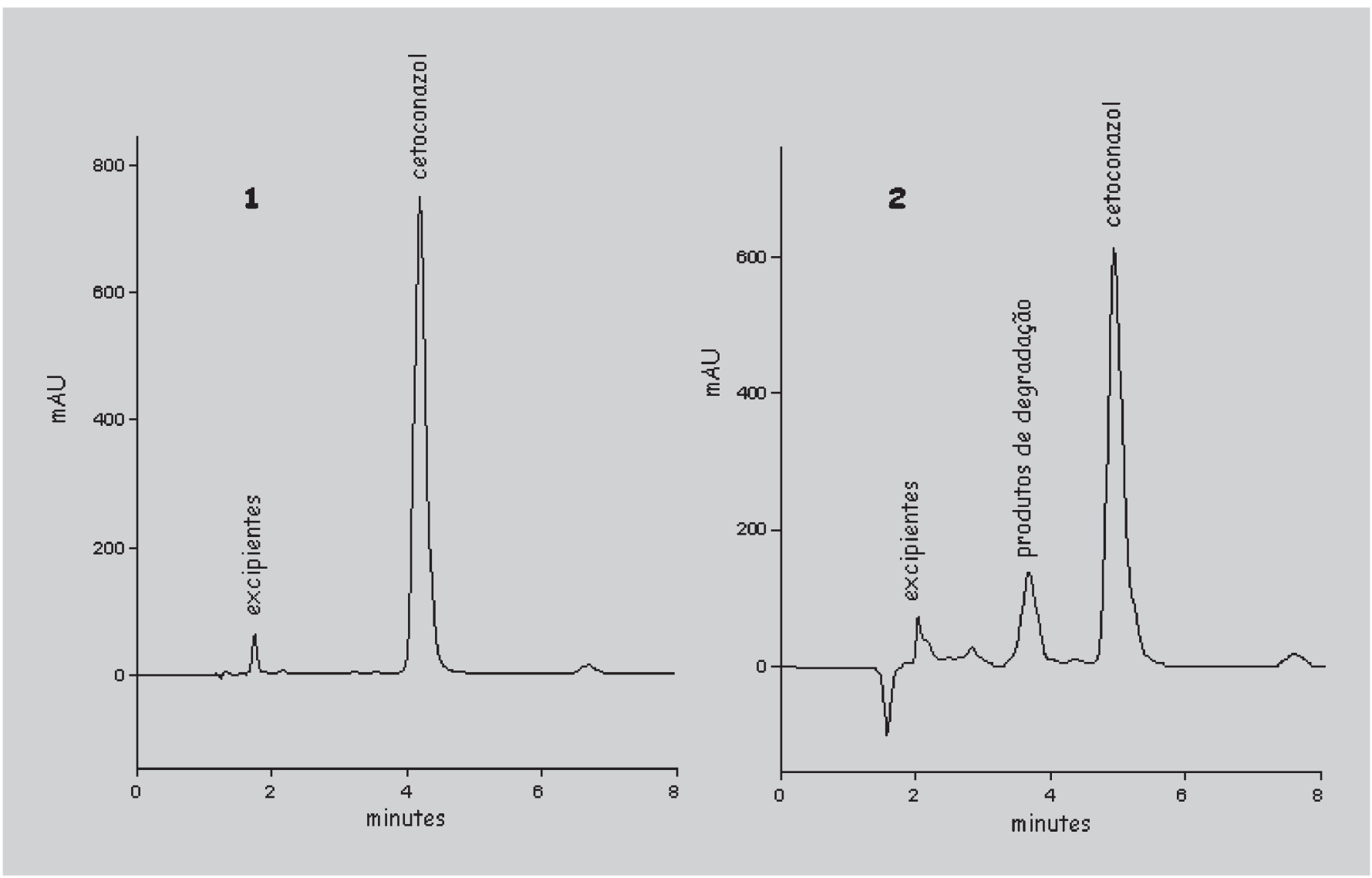

FIGURA 2 - 1) Cromatograma do cetoconazol xampu $(320 \mu \mathrm{g} / \mathrm{mL})$ e 2) cromatograma do cetoconazol xampu, após exposição à lâmpada UV-C por 24 horas (concentração teórica $320 \mu \mathrm{g} / \mathrm{mL}$ ), obtidos através de CLAE com comprimento de onda de $225 \mathrm{~nm}$, utilizando coluna de fase reversa C-8 e monoisopropilamina-metanol (2:500, v/v)/acetato de amônioágua $(1: 200, \mathrm{p} / \mathrm{v})(7: 3, \mathrm{v} / \mathrm{v}) \mathrm{pH} 5,5$ como fase móvel.

biológica (teste de irritação ocular) da formulação íntegra e formulação contendo produtos de degradação, para verificar se a presença destes alterava o grau de irritação do produto.

Os coelhos foram examinados $24,48,72$ horas e sete dias após a instilação do xampu no olho direito. Os resultados obtidos para as amostras encontram-se nas Tabelas I e II. A partir dos resultados obtidos, foi possível classificar o grau de irritação das formulações com auxílio da tabela de graduação do produto (Tabela III). Para o xampu não degradado (teor de 103,3\%) o produto mostrou-se irritante moderado (Classe III), da mesma forma, o xampu contendo os produtos de degradação (teor de 41,4\%) mostrou-se um produto irritante moderado (Classe III).

Para a avaliação da segurança biológica de xampus em geral, um teste amplamente empregado é o teste de irritação ocular em coelho. Entretanto, o teste de Draize, por utilizar animais, é bastante questionado devido ao intenso sofrimento dos mesmos. Segundo a Anvisa (2005), apesar dos esforços para redução e substituição de animais de laboratório na experimentação biológica, ainda não é possível abandonar a utilização desses animais na avaliação da segurança de produtos, nos seus mais diversos aspectos. De uma forma geral, recomenda-se que os animais de laboratório utilizados em experimentação sejam manuseados dentro dos preceitos éticos preconizados pelos Guias Internacionais como no Guide to the Care and Use of Experimental Animal (1992), de forma a contribuir para o refinamento dos ensaios e a diminuição do sofrimento a que possam ser submetidos durante a realização de ensaio biológicos. Atualmente, muitos estudos têm sido feitos para obtenção de métodos in vitro, que possam ser utilizados como substituição ao teste de irritação ocular.

Sendo assim, as culturas celulares assumem importância nos testes de toxicidade, pois são sensíveis, reprodutíveis, fáceis de estabelecer e gerenciar, com menores custos. Atualmente, sistemas de células encontram utilização para avaliar o potencial citotóxico de componentes 
TABELA I - Valores obtidos após o teste de irritação ocular, segundo escala de Draize, para amostra de xampu de cetoconazol a $2 \%$ não degradada

\begin{tabular}{ccccc}
\hline Coelho & 24 horas & 48 horas & 72 horas & 7 dias \\
\hline 1 & 21 & 17 & 10 & 2 \\
2 & 21 & 12 & 8 & 0 \\
3 & 33 & 24 & 17 & 4 \\
4 & 33 & 33 & 17 & 4 \\
5 & 23 & 17 & 8 & 2 \\
Média \pm DP & $26,20 \pm 6,26$ & $20,60 \pm 8,14$ & $12,00 \pm 4,63$ & $2,40 \pm 1,67$ \\
\hline
\end{tabular}

TABELA II - Valores obtidos após o teste de irritação ocular, segundo escala de Draize, para amostra de xampu de cetoconazol a $2 \%$ degradada

\begin{tabular}{ccccc}
\hline Coelho & 24 horas & 48 horas & 72 horas & 7 dias \\
\hline 1 & 21 & 15 & 8 & 2 \\
2 & 17 & 8 & 6 & 0 \\
3 & 19 & 17 & 6 & 2 \\
4 & 12 & 10 & 6 & 0 \\
5 & 12 & 10 & 6 & 0 \\
Média \pm DP & $16,20 \pm 4,09$ & $12,00 \pm 3,81$ & $6,40 \pm 0,89$ & $0,80 \pm 1,09$ \\
\hline
\end{tabular}

TABELA III - Classificação do produto após teste de irritação ocular (INCQS, 2002)

\begin{tabular}{|c|c|c|c|}
\hline Classe & $\begin{array}{c}\text { Índice de } \\
\text { irritação ocular }\end{array}$ & Classificação & Observações \\
\hline$I$ & $0-14,9$ & não irritante & $\mathrm{M} 24 \mathrm{~h}<2,4=$ Classe I; se M24h $>2,4$ ir p/ Classe II \\
\hline$I I$ & $15-24,9$ & irritante leve & $\begin{array}{l}\text { 1)M } 48 \mathrm{~h}<2,4=\text { Classe II, se } \mathrm{M} 48 \mathrm{~h}>2,4 \text { ir } \mathrm{p} / \text { item } 2 \\
\text { 2)M } 72 \mathrm{~h}<2,4=\text { Classe II, se } \mathrm{M} 72 \mathrm{~h}>2,4 \text { ir } \mathrm{p} / \text { Classe III }\end{array}$ \\
\hline III & $25-49,9$ & irritante moderado & $\begin{array}{l}\text { 1) } \mathrm{M} 7 \mathrm{~d}<20 \text { ir } \mathrm{p} / \text { item } 2 \text {, se } \mathrm{M} 7 \mathrm{~d}>20 \text { ir } \mathrm{p} / \text { Classe IV } \\
\text { 2) } \mathrm{L} 7 \mathrm{~d}<10 \text { em pelo menos } 3 \text { animais }=\text { Classe III, se } \mathrm{L} 7 \mathrm{~d}>30 \\
\text { em pelo menos } 1 \text { animal = Classe IV }\end{array}$ \\
\hline$I V$ & $50-79,9$ & irritante severo & $\begin{array}{l}\text { 1) } \mathrm{M} 7 \mathrm{~d}<40 \text { ir } \mathrm{p} / \text { item } 2 \text {, se } \mathrm{M} 7 \mathrm{~d}>40 \text { ir } \mathrm{p} / \text { Classe } \mathrm{V} \\
\text { 2) } \mathrm{L} 7 \mathrm{~d}<30 \text { em pelo menos } 3 \text { animais }=\text { Classe IV, se } \mathrm{L} 7 \mathrm{~d}>80 \\
\text { em pelo menos } 1 \text { animal }=\text { Classe } V\end{array}$ \\
\hline$V$ & $80-110$ & irritante máximo & $\begin{array}{l}\text { 1) } \mathrm{M} 7 \mathrm{~d}>40 \mathrm{ir} \mathrm{p} / \text { item } 2 \\
\text { 2)L } \mathrm{L} \mathrm{d}>60 \mathrm{em} \text { pelo menos } 1 \text { animal }=\text { Classe } \mathrm{V}\end{array}$ \\
\hline
\end{tabular}

L: leitura de cada coelho; M: média das leituras

cosméticos, materiais médico-hospitalares, produtos farmacêuticos e químicos. A citotoxicidade é baseada nos efeitos da substância-teste sobre a integridade celular, crescimento celular e alterações de parâmetros específicos bioquímicos ou fisiológicos (Pinto, Kaneko, Ohara, 2000).
Para a avaliação da segurança biológica do xampu de cetoconazol, contendo produtos de degradação, foi realizada, além do teste de irritação ocular, a avaliação do potencial de citotoxicidade in vitro para posterior comparação dos resultados obtidos entre os dois testes. 
TABELA IV - Valores dos índices de zona obtidos após a leitura das placas de culturas celulares, utilizando linhagem celular NCTC Clone 929 (ATCC CCL-1), para as amostras de xampu de cetoconazol a 2\% não degradado (ND) e degradado (D)

\begin{tabular}{ccccc}
\hline Placas & $\begin{array}{c}\text { IZ } \\
\text { Xampu (ND) } \\
(103,3 \%)\end{array}$ & $\begin{array}{c}\text { IZ } \\
\text { Xampu (D) } \\
(41,4 \%)\end{array}$ & $\begin{array}{c}\text { Controle } \\
\text { positivo }\end{array}$ & $\begin{array}{c}\text { Controle } \\
\text { negativo }\end{array}$ \\
\hline 1 & 4 & 4 & 4 & 0 \\
2 & 4 & 4 & 4 & 0 \\
3 & 4 & 4 & 4 & 0 \\
4 & 4 & 4 & 4 & 0 \\
\hline
\end{tabular}

IZ: índice de zona obtido após leitura das placas

Os resultados, após leitura dos halos formados, estão apresentados na Tabela IV. As duas formulações apresentaram severo efeito tóxico, ao redor da amostra, para a linhagem celular NCTC Clone 929 (ATCC CCL-1).

Verificou-se que os dois produtos analisados não tiveram diferença entre si, demonstrando que o xampu de cetoconazol contendo produtos de degradação não tem seu grau de irritação aumentado em relação à formulação na forma íntegra. Entretanto, observou-se diferença nos resultados obtidos entre os dois métodos empregados; isso pode ser explicado, pois segundo Wilhelmus (2001), os dados obtidos in vitro nem sempre correspondem corretamente aos resultados obtidos através de estudos in vivo.

O uso de animais em pesquisa e o desenvolvimento de métodos alternativos in vitro têm sido constantemente discutidos. Entretanto, até agora, nenhum teste in vitro, individualmente, teve aceitação plena como alternativo ao teste de Draize. Como no teste de irritação ocular há mais de um mecanismo envolvido, pois o olho é um sistema complexo, os resultados entre os métodos foram diferenciados, sendo os resultados in vitro mais elevados que os in vivo.

\section{CONCLUSÃO}

- O teste de irritação ocular em coelho demonstrou que a presença de produtos de degradação nas formulações, mesmo em quantidades elevadas, não aumentou a irritação ocular em coelho.

- A avaliação da citotoxicidade permitiu verificar que a presença dos produtos de degradação, mesmo em quantidades elevadas, não aumentou o grau de irritação das amostras.

- $\quad$ Os ensaios in vitro e in vivo não apresentaram os mesmos resultados indicando que um único ensaio in vitro não é suficiente para uma completa avaliação dos efeitos observados in vivo.

\section{AGRADECIMENTOS}

Lutz.

Os autores agradecem à CAPES, ao Instituto Adolfo

\section{ABSTRACT}

\section{Determination of the biological reactivity of ketoconazole in shampoo: Draize eye test and cytotoxity test}

Ketoconazole is an antifungal agent and can be incorporated into several dosage forms, as an example it could be mentioned shampoos and creams. The aim of this work was to assess the biological reactivity in vivo (Draize eye test) and in vitro (cytotoxity test) of ketoconazole in shampoo degradeted under action of light. The formulation was exposed to $U V-C(254 \mathrm{~nm})$ radiation and two methods were used for the quantitative determination of ketoconazole: HPLC and microbiological assay. The results showed alteration in ketoconazole in presence of light - secondary peaks in chromatogram and decrease in antifungal activity - however, no alteration on the biological reactivity between ketoconazole shampoo and ketoconazole shampoo containing degradation products was observed.

UNITERMS: Ketoconazole. Shampoo. Degradation products. Draize eye test. Cytotoxity test.

\section{REFERÊNCIAS BIBLIOGRÁFICAS}

ALLEN, L.V.; ERICKSON, M.A. Stability of ketoconazole, metolazone, metronidazole, procainamide hydrochloride and spirinolactone in extemporaneously compounded oral liquids. Am. J. Health Syst. Pharm., v. 53, p. 2073-2078, 1996. 
ANVISA. AGÊNCIA NACIONAL DE VIGILÂNCIA SANITÁRIA. Guia para avaliação de segurança de produtos cosméticos. Disponível em: <http:// www.anvisa.gov.br/cosmeticos/guia/html $>$. Acesso em: 12 dez. 2005.

BENETT, J.E. Fármacos antimicrobianos. In: HARDMAN, J.G.; LIMBIRD, L.E.; MOLINOFF, P.B.; RUDDON, R.W.; GILMAN, A.G., eds. Goodman \& Gilman's as bases farmacológicas da terapêutica. $9 \mathrm{ed}$. Rio de Janeiro: MacGraw-Hill Interamericana, 1996. cap. 49, p. $864-875$.

DRAIZE, J.H.; WOODARD, G.; CALVERY, H.O. Methods for the study of irritation and toxicity of substances applied topically to the skin and mucous membranes. $J$. Pharmacol. Exp. Ther, v. 82, p. 377-390, 1944.

FARMACOPÉIA Brasileira. 4 ed. São Paulo: Atheneu, 1988. pt.1, p.VI.5.2, VI.5.3, VI.9

GUPTA, A.K.; MADZIA, S.E.; BATRA, R. Etiology and management of seborrheic dermatitis. Dermatology, v. 208, n. 2, p. 89-93, 2004.

HEWITT, W. Microbiological assay: an introduction to quantitative principles and evaluation. New York: Academic Press, 1977. p. 284

INCQS. INSTITUTO NACIONAL DE CONTROLE DE QUALIDADE EM SAÚDE. Manual n. 66.3330.0004. Rio de Janeiro, 2002.

KLENK, A.S.; MARTIN, A.G.; HEFFERNAN, M.P. Yeast infections: candidiasis, pityriasis versicolor. In: FREEDBERG, I.M.; EISEN, A.Z.; WOLFF, K.; AUSTEN, K.F.; GOLDSMITH, L.A.; KATZ, S.I. Fitzpatrick's dermatology in general medicine. 6. ed. New York: MacGraw-Hill 2003. cap. 206. p. 2006-2017.

LACHMAN, L., LIEBERMAN, H.A., KANIG, J.L. Teoria e prática na indústria farmacêutica. Lisboa: Fundação Calouste, 2001. 1517p.

NATIONAL INSTITUTES OF HEALTH. Guide to the care and use of experimental animal. Disponível em: < http:/ /www.nap.edu/readingroom/books/labrats/chaps.html >. Acesso em: 22 maio. 2007.

NUDELMAN, N.S. Introdução. In: Estabilidad de medicamentos. Buenos Aires: El Ateneu; 1975. cap.1., p. $1-4$.
PINTO, T.J.A ; KANEKO, T.M.; OHARA, M.T. Ensaios toxicológicos e de inocuidade. In: Controle biológico de qualidade de produtos farmacêuticos, correlatos e cosméticos. São Paulo: Atheneu; 2000. cap. 9, p. 275-309.

SKIBA, M.; SKIBA-LAHIANI, M.; MARCHAIS, H.; DUCLOS, R.; ARNAUD, P. Stability assessment of ketoconazole in aqueous formulations. Int. J. Pharm., v. 198, p. $1-6,2000$.

STAUB, I.; ADAMS, A.I.H.; BERGOLD, A.M.; FRÖEHLICH, P. Avaliação da integridade da fórmula do xampu de cetoconazol. Infarma, v. 14, p.74-76, 2002.

STAUB, I.; BERGOLD, A.M. Determination of ketoconazole in shampoo by high performance liquid chromatography. Acta Farm. Bonaerense, v. 23, n. 3, p. 387-390, 2004.

STAUB, I.; SCHAPOVAL,E.E.S.; BERGOLD, A.M. Microbiological assay of ketoconazole in shampoo. Int. J. Pharm., v. 292, p. 195-199, 2005.

STAUB, I. Avaliação da fotoestabilidade do cetoconazol e determinação da atividade antifúngica e da segurança biológica in vivo e in vitro do xampu de cetoconazol. Porto Alegre, 2005.224p. [Tese de Doutorado. Faculdade de Farmácia. Universidade Federal do Rio Grande do Sul].

THOMA, K.; KÜBLER, N. Unterschung der photostabilität von antimykotika 1. Mitteilung: Photostabilität von Polyenantibiotika. Pharmazie, v. 51, p. 885-893, 1996.

TONNESSEN, H.H. Formulation and stability testing of photolabile drugs. Int. J. Pharm., v. 225, p. 1-14, 2001.

UNITED States Pharmacopoeia. 28.ed. Rockwille: United States Pharmacopeial Convention, 2005. p. 2268-2269

WATSON, D.G. High pressure liquid chromatography. In: Pharmaceutical analysis. A textbook for pharmacy students and pharmaceutical chemists. 2 ed. Edinburgh: Elsevier Churchill Livingstone, 2005. cap. 12.p. 237-274.

WILHELMUS, K.R. The Draize eye test. Surv. Ophthalmol., v. 45 , n. 6, p. 493-515, 2001.

Recebido para publicação em 15 de fevereiro de 2006. Aceito para publicação em 16 de abril de 2007. 